\title{
Pengendalian Risiko Ergonomi Kasus Low Back Pain pada Perawat di Rumah Sakit
}

\author{
L. Meily Kurniawidjaja, ${ }^{1,2}$ Edy Purnomo, ${ }^{3}$ Nadia Maretti, ${ }^{3}$ Ike Pujiriani ${ }^{1}$ \\ ${ }^{1}$ Pusat Kajian dan Terapan Keselamatan dan Kesehatan Kerja, Fakultas Kesehatan Masyarakat \\ Universitas Indonesia, ${ }^{2}$ Departemen Keselamatan dan Kesehatan Kerja, Fakultas Kesehatan \\ Masyarakat Universitas Indonesia, ${ }^{3}$ Program Studi Magister Keselamatan dan Kesehatan Kerja, \\ Fakultas Kesehatan Masyarakat Universitas Indonesia
}

\begin{abstract}
Abstrak
Perawat berisiko tinggi nyeri pinggang bawah. Tujuan penelitian ini menilai faktor risiko akivitas fisik dan sarana kerja yang dominan dapat menimbulkan low back pain (LBP) pada perawat di ruang Rawat Inap dan Unit Gawat Darurat Rumah Sakit di Jakarta serta memberikan rekomendasi pengendalian risiko LBP. Observasi dilakukan untuk mengidentifikasi aktivitas berisiko tinggi LBP, metode rapid entirebody assessment (REBA) menilai tingkat risiko ergonomi, kuesioner dan Nordic body map menilai faktor risiko lainnya serta keluhan LBP, desain potong lintang untuk analisis asosiasi, pengukuran dan analisis untuk menilai alat kerja. Hasil penelitian mendapatkan prevalensi LBP cukup tinggi pada perawat UGD di RSUD Tarakan tahun 2013 (61,1\%) dan perawat rawat inap di RS Bhayangkara tahun $2012(31,8 \%)$, namun rendah pada perawat UGD di RSS bila dibandingkan dengan hasil survei global (43,1-87\%); aktivitas yang dominan menimbulkan LBP adalah membungkuk dan angkat angkut pasien. Didapatkan hubungan yang bermakna postur membungkuk $(\mathrm{p}=0,031 ; \mathrm{OR}=1,18-133,89)$, sudut lengkung punggung $(\mathrm{p}=0,024 ; \mathrm{OR}=1,65-196,31)$, dan transfer pasien $(\mathrm{p}=0,011 ; \mathrm{OR}=5,22-176,83)$ dengan tingkat risiko LBP. Simpulan, aktivitas fisik perawat dan sarana kerjanya dapat menyebabkan LBP sehingga disarankan menyediakan sarana kerja yang adjustable serta 'meja' dinding di toilet untuk pengukuran urin, memenuhi rasio perawat-pasien minimal, SOP, mendidik perawat agar mampu melakukan pengendalian. [MKB. 2014;46(4):225-33]
\end{abstract}

Kata kunci: Ergonomi, low back pain, perawat

\section{Ergonomic Risk Control on Low Back Pain among Hospitals' Nurses}

\begin{abstract}
Nurses are at high risk of low back pain (LBP). This study aimed to assess physical activities and working facilities as the risk factors that can lead to LBP in nurses in the wards and the emergency units of several hospitals in Jakarta to provide recommendations for controlling the risk of LBP. Observations were performed to identify high-risk activities and the rapid entire body assessment (REBA) method was used to assess the ergonomic risk. Questionnaires and Nordic body map were also used to assess the other risk factors and LBP-related complaints. In addition, the cross-sectional design for association analysis, measurement and analysis to assess the working tools were also applied. The results showed that the prevalence of LBP among nurses was higher in the RSUD Tarakan emergency unit in $2013(61.1 \%)$ and RS Bhayangkara wards in $2012(31.8 \%)$. In the private hospital emergency unit, the LBP is lower compared to the results of a global survey $(43.1-87 \%)$. The dominant causes of LBP were bending and patient-lifting. A significant association was evident between the risk level of LBP and bending posture $(\mathrm{p}=0.031, \mathrm{OR}=1.18-133.89)$, curved spine angle $(\mathrm{p}=0.024, \mathrm{OR}=1.65-196.31)$, and patients transfer $(\mathrm{p}=0.011, \mathrm{OR}=5.22-176.83$ ). In conclusion, nurse physical activities and their work facilities can induce LBP. Therefore, it is suggested to provide adjustable facilities and wall-mounted tables in the toilets for urine measurements. Meeting the the minimum nurse: patient ratio, providing SOPs, and educating the nurses to control the risks of LBP are also needed. [MKB. 2014;46(4):225-33]
\end{abstract}

Key words: Ergonomic, low back pain, nurse

Korespondensi: Dr. L. Meily Kurniawidjaja, dr., M.S, Sp.OK, Pusat Kajian dan Terapan Keselamatan dan Kesehatan Kerja Fakultas Kesehatan Masyarakat Universitas Indonesia, Jalan Kampus Baru Universitas Indonesia Depok, mobile 08161115022, e-mail meily.widjaja@gmail.com 


\section{Pendahuluan}

Low back pain (LBP) atau nyeri pinggang bawah adalah salah satu masalah kesehatan kerja yang paling sering ditemukan ${ }^{1}$ dan dapat menimbulkan absenteisme tertinggi di tempat kerja. ${ }^{1-3}$ Pekerja berisiko tingggi LBP adalah pekerja yang bekerja dengan postur janggal, manual handling serta dengan frekuensi dan durasi yang tinggi termasuk pekerja kesehatan di rumah sakit, terutama pada perawat di area kerja yang banyak mengangkat. ${ }^{4}$ Banyak penelitian di dunia melaporkan perawat merupakan salah satu pekerjaan berisiko tinggi LBP, ${ }^{5}$ Hignett pada tahun 1996 merangkum 80 penelitian yang dipublikasi selama tiga dekade, menemukan prevalensi LBP perawat lebih tinggi daripada populasi umum, terutama perawat yang banyak melakukan kegiatan angkat-angkut atau mobilisasi pasien. ${ }^{6,7}$ Hasil penelitian Hignett masih relevan, keadaan ini ditunjukkan dalam publikasi terkini pada tahun 2013 berupa Global Health Research Program yang dilaksanakan oleh The University of British Columbia Canada; mereka merangkum 89 penelitian yang dipublikasi tahun 1980-2012 terdiri atas berbagai macam desain penelitian, baik yang longitudinal maupun potong lintang, bersifat analitik atau deskriptif di bidang ergonomik, termasuk studi review. Hasil review Global Research ini juga menunjukkan aktivitas perawat berhubungan dengan peningkatan risiko gangguan tulang belakang, terutama aktivitas angkat-angkut atau mobilisasi pasien. Hubungan ini memenuhi postulat Hill yaitu asosiasi yang kuat, konsisten, temporal, plausible, koheren, dan analog dengan hubungan pajanan-luaran; estimasi risiko LBP 1,2-5,5 kali bila dibandingkan dengan populasi umum. ${ }^{8}$

Dehlin dkk. (1976) dalam studi yang dilakukan di rumah sakit geriatri di Swedia, mendapatkan prevalensi LBP pada perawat sebanyak 47\%, Stubbs dkk. (1983) di Inggris membuktikan bahwa selama setahun, perawat yang mengalami keluhan LBP sebanyak 43,1\%, Arad dkk.(1986) di Rumah Sakit RNH mendapatkan 87\% insidensi LBP pada 1.033 perawat. Faktor fisik, seperti posisi janggal, manual handling, sering membungkuk dan memutar serta gerakan mendorong ke depan merupakan faktor risiko yang dapat memengaruhi tingginya prevalensi LBP tersebut.'

Tahun 2005, kajian Depertemen Kesehatan Republik Indonesia mendapatkan bahwa 40,5\% pekerja informal memiliki keluhan yang diduga terkait dengan pekerjaannya, prevalensi yang paling tinggi yaitu penyakit otot rangka (16\%). Pada tahun 2006, berdasarkan hasil kajian tentang pembiayaan jaminan kesehatan bagi para pekerja sektor informal diperoleh keluhan paling banyak dalam 1 (satu) bulan terakhir adalah pegal-pegal $(67 \%) .{ }^{10}$

Sebanyak $65 \%$ perawat di UGDRS Fatmawati Jakarta didiagnosis menderita LBP, sedangkan rekam medik di RS Prikasih pada JanuariDesember 2010 menunjukkan bahwa perawat yang terkena LBP sebanyak 59 orang $(34,7 \%)$. Hasil penelitian Cropcord Indonesia tahun 2004 menunjukkan bahwa prevalensi penderita LBP pada pria sebanyak $18,2 \%$ dan wanita sebanyak $13,6 \% .^{11}$ Pimpinan rumah sakit bertanggung jawab pada keselamatan dan kesehatan kerja, berkewajiban melakukan manajemen kasus LBP sebagai wujud perlindungan hak asasi pekerja sesuai peraturan perundangan, ${ }^{12}$ dalam rangka mencegah kerugian finansial dan nonfinansial baik bagi pekerja maupun rumah sakit. Manajemen kasus LBP merupakan serangkaian kegiatan multidisiplin yang menyeluruh, yaitu peningkatan, pencegahan, pengobatan dan pemulihan, salah satu upaya pencegahan LBP adalah melakukan perbaikan pada sumbernya yaitu menurunkan risiko dengan cara memperbaiki ergonomi sarana dan prasarana kerja, serta mempertimbangkan keterbatasan manusia dan gangguan kesehatan yang dapat diakibatkannya.

Hasil prasurvei awal tahun 2012 di beberapa rumah sakit di Jakarta memperlihatkan, perawat di rumah sakit yang paling banyak pekerjaan angkat angkut pasien adalah di unit kerja yang memberikan pelayanan 24 jam yaitu di ruang Rawat Inap dan di Unit Gawat Darurat. Wawancara dengan Kepala Subbagian Administrasi di RS Bhayangkara mendapatkan 8 orang perawat di Instalasi Tahanan menderita LBP dan sering sekali tidak hadir. Data kunjungan poli karyawan RSUD Tarakan Jakarta pada tahun 1990-2012 didapatkan 18 perawat yang menderita HNP, 5 di antaranya sudah menjalani operasi laminektomi; sebaliknya di RSS tidak terdapat perawat yang mengeluh LBP atau menderita kelainan HNP. Tujuan penelitian ini adalah menilai faktor risiko akivitas fisik dan sarana kerja yang dominan dapat menimbulkan LBP pada perawat di ruang Rawat Inap dan di Unit Gawat Darurat rumah sakit di Jakarta serta memberikan rekomendasi tentang pengendalian, sedangkan tujuan khususnya yaitu (1) identifikasi pekerjaan, tugas atau aktivitas fisik yang berisiko menimbulkan LBP; (2) menilai insidensi keluhan LBP; (3) menilai tingkat risiko ergonomi menurut akitivitas perawat; (4) analisis asosiasi karakteristik individu dan keluhan LBP; (5) analisis asosiasi faktor risiko ergonomi dan keluhan LBP; (6) identifikasi dan menilai sarana kerja yang dominan menimbulkan LBP; dan (7) memberikan rekomendasi pengendalian. 


\section{Metode}

Subjek penelitian adalah perawat yang memberi pelayanan pasien di ruang Rawat Inap dan Unit Gawat Darurat, mereka adalah kelompok terpajan yang paling sering mengangkat dan mengangkut pasien yang memiliki keterbatasan gerak fisik dan membutuhkan bantuan perawat. Penelitian ini mempergunakan metode studi kasus dengan desain potong lintang. Variabel independen yang diteliti adalah faktor risiko ergonomi dan variabel dependennya adalah tingkat risiko ergonomi serta keluhan LBP.

Penelitian ini dilakukan pada tahun 20122013, di tiga rumah sakit yang terdiri atas dua rumah sakit pemerintah yaitu rumah sakit militer (RS Bhayangkara) dan rumah sakit sipil yang dikelola oleh pemerintah daerah DKI-Jakarta (RSUD Tarakan), dan satu rumah sakit swasta RSS (nama rumah sakit tidak bersedia dipublikasikan). Kriteria inklusi rumah sakit adalah cukup banyak pasiennya, mempekerjakan minimal 15 orang perawat masing-masing di ruang rawat inap atau ruang gawat darurat, bersedia diteliti, terletak di Jakarta, kriteria eksklusinya adalah rumah sakit yang baru memberi pelayanan kurang dari 5 (lima) tahun, atau sulit untuk dijangkau dengan kendaraan umum.

Populasi penelitian ini adalah perawat di RS terpilih, kriteria inklusinya adalah perawat yang sudah bekerja minimal satu tahun di bagian UGD dan/atau ruang rawat inap, bersedia mengikuti penelitian dengan menandatangani persetujuan ikut penelitian (informed consent), sedangkan kriteria eksklusinya pada penelitian ini adalah perawat yang bekerja belum satu tahun, sedang hamil, mempunyai riwayat penyakit yang kronik seperti diabetes melitus, dan/atau mempunyai keluhan LBP sebelum bekerja. Sampel penelitian adalah seluruh populasi yang memenuhi syarat penelitian, yaitu 22 perawat Ruang Rawat Inap di RS Bhayangkara, 36 perawat UGD di RSUD Tarakan, dan 16 perawat di RSS.

Ketiga rumah sakit yang telah memberikan izin, dinilai dan dipilih sesuai dengan kelengkapan data, sarana, serta kemungkinan untuk diteliti. Untuk identifikasi pekerjaan, tugas atau aktivitas fisik yang berisiko menimbulkan LBP, serta penilaian tingkat risiko ergonomi. Penelitian ini dilakukan di ruang Instalasi Rawat Tahanan di RS Bhayangkara dan Instalasi Gawat Darurat RSUD Tarakan; sedangkan untuk analisis asosiasi faktor risiko ergonomi dengan keluhan LBP hanya berhasil dilaksanakan di Instalasi Rawat Tahanan di Rumah Sakit Bhayangkara. Untuk menilai sarana kerja dominan yang teridentifikasi berisiko menimbulkan LBP dilakukan di ketiga rumah sakit tersebut. Penelitian ini terdiri atas empat tahap seperti berikut.

Tahap pertama adalah penilaian proses kerja untuk mengidentifikasi aktivitas pekerjaan yang berisiko tinggi LBP, dilakukan dengan metode observasi dan didokumentasi dengan kamera dan video digital.

Tahap kedua adalah penilaian tingkat risiko ergonomi, yaitu dengan penilaian postur janggal, frekuensi, durasi dan beban dilakukan dengan metode rapid entire body assessment (REBA) ${ }^{13}$ pada pekerjaan yang teridentifikasi berisiko tinggi LBP, diteruskan dengan penyebaran kuesioner dan wawancara kepada perawat untuk menilai faktor risiko LBP lainnya serta penilaian keluhan LBP dengan menggunakan Nordic body map.

Tahap ketiga dilakukan analisis asosiasi antara faktor risiko ergonomi (termasuk karakteristik individu) dan tingkat risiko/ keluhan LBP dengan menggunakan desain penelitian potong lintang,

Tahap keempat, dengan penilaian faktor risiko alat dan juga sarana yang teridentifikasi berasosisi kuat dengan tingkat risiko LBP, mempergunakan alat ukur yang sesuai seperti meteran, timbangan, dan busur.

Analisis univariat disajikan dalam bentuk tabel distribusi frekuensi dan narasi secara kualitatif, sedangkan analisis bivariat dilakukan dengan uji kai-kuadrat.

\section{Hasil}

Data primer hasil observasi mendapatkan aktivitas pekerjaan perawat yang berisiko menimbulkan LBP di Ruang Rawat dan UGD yaitu seperti berikut.

Pekerjaan dengan posisi membungkuk, yaitu saat memasang dan melepaskan infus, suction menghisap lender, klisma, merawat dan menjahit luka atau mengganti balutan, resusitasi jantung paru, memasang dan mencabut serta memberi makan pasien via nasogastric tube, mengambil sampel darah, memandikan pasien, memberikan terapi injeksi, serta memasang atau memperbaiki

Tabel 1 Insiden Keluhan LBP pada Perawat dalam 12 Bulan di Tiga Rumah Sakit

\begin{tabular}{lccc}
\hline \multirow{2}{*}{$\begin{array}{c}\text { Keluhan } \\
\text { LBP }\end{array}$} & $\begin{array}{c}\text { RS } \\
\text { Bhayangkara } \\
\text { (R. Rawat) }\end{array}$ & $\begin{array}{c}\text { RSUD } \\
\text { Tarakan } \\
\text { (UGD) }\end{array}$ & $\begin{array}{c}\text { RSS* } \\
\text { (UGD) }\end{array}$ \\
\cline { 2 - 4 } Tidak & Jumlah & Jumlah & Jumlah \\
Ya & 15 & 14 & 15 \\
Total & 7 & 22 & 1 \\
\hline
\end{tabular}

Keterangan: *Salah satu rumah sakit swasta di Jakarta 
L. Meily K.: Pengendalian Risiko Ergonomi Kasus Low Back Pain pada Perawat di Rumah Sakit

Tabel 2 Tingkat Risiko Ergonomi dan Keluhan LBP Menurut Aktivitas Perawat

\begin{tabular}{lccc}
\hline \multicolumn{1}{c}{ Aktivitas Perawat } & $\begin{array}{c}\text { Skor } \\
\text { REBA }\end{array}$ & $\begin{array}{c}\text { Tingkat Risiko } \\
\text { Ergonomi }\end{array}$ & Keluhan LBP \\
\hline $\begin{array}{l}\text { Pengukuran tekanan darah } \\
\text { pasien }\end{array}$ & 3 & Rendah & - \\
Pemasangan infus pasien & 6 & Menengah & $80 \%$ \\
Pemasangan kateter pasien & 8 & Menengah & - \\
Menjahit luka pasien & 7 & Menengah & - \\
Membuang urin pasien & 10 & Tinggi & $80 \%$ \\
Mengangkat dan memindahkan & 11 & Sangat Tinggi & \\
pasien
\end{tabular}

spalk, memasang kateter, dan membuang urin.

Pekerjaan yang berhubungan memindahkan pasien dari brankar transportasi ke tempat tidur ataupun sebaliknya, antara lain yaitu pada saat menerima pasien baru ambulans atau dari Unit
Gawat Darurat, mengantar atau menerima pasien dari ruang operasi, mengantarkan pasien untuk pemeriksaan radiologi atau pemeriksaan lainnya dan menerima kembali pasien, mengirim pasien untuk rujukan ke rumah sakit lain.

Tabel 3 Hubungan Karakteristik Individu dengan Keluhan LBP Perawat di RS Bhayangkara (2012)

\begin{tabular}{|c|c|c|c|c|c|}
\hline \multirow[t]{2}{*}{ Karakteristik Individu } & \multicolumn{2}{|c|}{ Keluhan LBP } & \multirow[t]{2}{*}{ OR } & \multirow[t]{2}{*}{$95 \%$ IK } & \multirow{2}{*}{$\begin{array}{c}\text { Nilai } \\
\mathbf{p}\end{array}$} \\
\hline & Ya & Tidak & & & \\
\hline \multicolumn{6}{|l|}{ Usia (tahun) } \\
\hline$<35$ & 6 & 6 & 3,00 & $0,53-17,16$ & 0,634 \\
\hline$\geq 35$ & 6 & 4 & & & \\
\hline \multicolumn{6}{|l|}{ Jenis kelamin } \\
\hline Laki-laki & 7 & 8 & 0,18 & $0,03-0,23$ & $0,043 *$ \\
\hline Perempuan & 5 & 2 & & & \\
\hline \multicolumn{6}{|l|}{ IMT } \\
\hline Normal & 5 & 5 & 0,71 & $0,13-3,87$ & 1,000 \\
\hline Overweight & 7 & 5 & & & \\
\hline \multicolumn{6}{|l|}{ Tinggi badan $(\mathrm{cm})$} \\
\hline$<155$ & 1 & 7 & 25,67 & $2,21-298,49$ & $0,006^{*}$ \\
\hline$\geq 155$ & 11 & 3 & & & \\
\hline \multicolumn{6}{|l|}{ Kebiasaan merokok } \\
\hline $\mathrm{Ya}$ & 8 & 3 & 24,67 & $1,77-288,45$ & $0,019 *$ \\
\hline Tidak & 4 & 7 & & & \\
\hline \multicolumn{6}{|l|}{ Kebiasaan olah raga } \\
\hline Ya & 2 & 2 & 0,80 & $0,09-7,00$ & 1,00 \\
\hline Tidak & 10 & 8 & & & \\
\hline \multicolumn{6}{|l|}{ Kebiasaan stretching } \\
\hline Ya & 6 & 6 & 0,67 & $0,12-3,64$ & 0,691 \\
\hline Tidak & 6 & 4 & & & \\
\hline
\end{tabular}


Tabel 4 Hubungan Hazard Ergonomi dengan Tingkat Risiko Ergonomi dan Keluhan LBP Perawat di RS Bhayangkara Tahun 2012

\begin{tabular}{|c|c|c|c|c|c|c|c|c|}
\hline \multirow{2}{*}{$\underset{\text { Ergonomi }}{\text { Hazard }}$} & \multicolumn{2}{|c|}{$\begin{array}{c}\text { Tingkat Risiko } \\
\text { Ergonomi }\end{array}$} & \multirow{2}{*}{$\begin{array}{c}\text { OR } \\
(\mathbf{9 5 \%} \\
\text { IK) }\end{array}$} & \multirow{2}{*}{$\begin{array}{c}\text { Nilai } \\
\mathbf{p}\end{array}$} & \multicolumn{2}{|c|}{ Keluhan LBP } & \multirow{2}{*}{$\begin{array}{c}\text { OR } \\
\text { (95\% } \\
\text { IK) }\end{array}$} & \multirow{2}{*}{$\underset{\mathbf{p}}{\text { Nilai }}$} \\
\hline & Sedang & Tinggi & & & Ya & Tidak & & \\
\hline \multicolumn{9}{|l|}{$\begin{array}{l}\text { Postur kerja } \\
\text { membungkuk }\end{array}$} \\
\hline Tidak & 7 & 1 & 12,60 & 0,031 & 2 & 6 & 14,65 & 0,025 \\
\hline Ya & 5 & 9 & $(1,19-133,89)$ & & 10 & 4 & $(1,37-148,46)$ & \\
\hline \multicolumn{9}{|l|}{$\begin{array}{l}\text { Sudut lengkung } \\
\text { punggung }\end{array}$} \\
\hline$<60^{\circ}$ & 8 & 1 & 18,00 & 0,024 & 2 & 7 & 11,66 & 0,017 \\
\hline$\geq 60^{\circ}$ & 4 & 9 & $(1,65-196,31)$ & & 10 & 3 & $(1,53-89,12)$ & \\
\hline \multicolumn{9}{|l|}{ Transfer pasien } \\
\hline$\leq 3 \mathrm{x}$ & 8 & 1 & 96,00 & 0,011 & 3 & 10 & 4,33 & 0,002 \\
\hline$>3 x$ & 1 & 12 & $(5,22-176,83)$ & & 9 & 0 & $(1,61-11,69)$ & \\
\hline
\end{tabular}

Dari kuesioner dan wawancara yang divalidasi berdasarkan rekam medik, didapatkan insidensi tertinggi LBP adalah di Unit Gawat Darurat RSUD Tarakan, kemudian di Ruang Rawat RS Bhayangkara dan terendah adalah di Unit Gawat Darurat RSS (Tabel 1).

Skor akhir penilaian dengan metode REBA didaSkor akhir penilaian dengan metode REBA didapatkan tingkat risiko sangat tinggi pada aktivitas mengangkat dan memindahkan pasien, sedangkan tingkat risiko tinggi pada aktivitas membuang urin pasien (Tabel 2). LBP banyak dikeluhkan setelah memasang infus dan angkat angkut pasien, yaitu terdapat 29 dari 36 responden mengeluh LBP. Semua responden terlibat dalam semua aktivitas pekerjaan (multitasking) namun dengan intensitas dan kekerapan yang berbeda bergantung tugas pokok masing-masing jabatan, hasil penelitian mendapatkan 20 dari 36 responden berisiko sedang dan 16 dari 36 responden berisiko tinggi terkena LBP.

Perawat yang bekerja di Ruang Rawat Inap Tahanan RS Bhayangkara yang berjumlah 22 orang, 10 responden di antaranya berusia $\geq 35$ tahun, 12 responden overweight, 14 responden mempunyai tinggi badan lebih dari $155 \mathrm{~cm}, 15$ responden adalah laki-laki, 18 responden tidak mempunyai kebiasaan berolahraga, 12 responden meregangkan otot (stretching) secara berkala di sela-sela pekerjaannya, dan 11 dari 15 responden

Tabel 5 Dimensi Tempat Tidur dan Brankar Transportasi di RS Bhayangkara, RSUD Tarakan, dan RSS

\begin{tabular}{lcccccc}
\hline & \multicolumn{2}{c}{ RS Bhayangkara } & \multicolumn{2}{c}{ RSUD Tarakan } & \multicolumn{2}{c}{ RSS } \\
\cline { 2 - 7 } Dimensi & $\begin{array}{c}\text { Brankar } \\
\text { Transportasi }\end{array}$ & $\begin{array}{c}\text { TT Pasien } \\
\text { Rawat }\end{array}$ & $\begin{array}{c}\text { Brankar } \\
\text { Transportasi }\end{array}$ & $\begin{array}{c}\text { TT Pasien } \\
\text { Rawat }\end{array}$ & $\begin{array}{c}\text { Brankar } \\
\text { Transportasi* }\end{array}$ & $\begin{array}{c}\text { TT Pasien } \\
\text { Rawat** }\end{array}$ \\
\hline Tinggi (cm) & 80 & 50 & 85 & 60 & $63-95$ & $45-72$ \\
Panjang (cm) & 198 & 200 & 198 & 20 & 210 & 200 \\
Lebar (cm) & 64 & 90 & 64 & 90 & 85 & 90 \\
Adjustability & Tidak & Tidak & Tidak & Tidak & Ya & Ya \\
\hline
\end{tabular}

Keterangan: TT $=$ tempat tidur; *Beroda; **Beroda; sudut lipat bagian atas $($ back section $): 0 \sim 80^{\circ}\left( \pm 5^{\circ}\right)$; sudut lipat bagian bawah (leg section): $0 \sim 40^{\circ}\left( \pm 5^{\circ}\right)$ 
laki-lakinya merokok. Perawat yang berjumlah 22 orang ini bila dihubungkan dengan keluhan LBP, maka didapatkan karakteristik individu yang berhubungan bermakan dengan LBP adalah tinggi badan, kebiasaan merokok, serta jenis kelamin (Tabel 3).

Hasil analisis bivariat mendapatkan bahwa semua faktor risiko ergonomi itu berhubungan dengan tingkat risiko dan keluhan LBP, yaitu postur kerja membungkuk berisiko 14 kali lebih sering terjadi keluhan LBP bila dibandingkan dengan postur kerja tidak membungkuk; sudut lengkung punggung $\geq 60^{\circ}$ berpeluang $11 \mathrm{kali}$ lebih sering terjadi keluhan LBP bila dibandingkan dengan sudut lengkung punggung lebih kecil dari $60^{\circ}$, dan transfer pasien 3 kali atau lebih per hari berpeluang 4 kali lebih sering terjadi keluhan LBP dibandingkan dengan transfer pasien kurang dari 3 kali per hari (Tabel 4).

Hasil observasi menunjukkan bahwa tempat tidur yang rendah dan tidak dapat disesuaikan dengan tinggi badan perawat, juga jarak antara tinggi tempat tidur dan brankar sebesar 15-20 $\mathrm{cm}$ (Tabel 5), menyebabkan perawat di RS Bhayangkara dan RSUD Tarakan bekerja dengan postur kerja membungkuk, akan menambah sudut lengkung punggung terutama bagi perawat yang tinggi badannya.

\section{Pembahasan}

Perawat adalah profesi dengan pekerjaan berisiko tinggi LBP, karena aktivitas perawat berhubungan dengan peningkatan risiko pada gangguan tulang belakang terutama aktivitas angkat-angkut atau mobilisasi pasien, ${ }^{14,15}$ dan juga pekerjaan dengan postur yang membungkuk. ${ }^{16}$ Pada penelitian ini, teridentifikasi pula pekerjaan angkat angkut dan mobilisasi pasien berisiko tinggi LBP, selain itu juga teridentifikasi pekerjaan yang dilakukan dengan membungkuk antara lain menjahit luka, memasang infus, dan mengukur urin.

Hasil penelitian jika dibandingkan dengan prevalensi LBP tahun 2004 pada masyarakat umum di Indonesia yaitu pada pria sebanyak 18,2\% dan wanita sebanyak $13,6 \%,{ }^{11}$, maka prevalensi LBP lebih tinggi pada perawat, yang paling tinggi ditemukan pada perawat di UGD RSUD Tarakan (61,1\%), kemudian di Ruang Rawat Tahanan Rumah Sakit Bhayangkara (31,8\%), sedangkan di UGD RSS lebih rendah $(6,25 \%)$, hal ini sejalan dengan hasil penelitian global, yaitu secara umum estimasi risiko LBP pada perawat adalah 1,2-5,5 kali bila dibandingkan dengan populasi umum, ${ }^{8}$ prevalensi LBP pada perawat adalah $43,1-87 \%{ }^{7}$ Tingginya prevalensi LBP yang ditemukan pada responden penelitian ini sesuai dengan temuan hasil review 80 penelitian selama tiga dekade terakhir pada tahun 1996, dan 89 penelitian global dalam kurun waktu 1980-2012. Tercatat di Australia prevalensi LBP perawat $42 \%$; di rumah sakit geriatri di Swedia 47\%; di Inggris 43,1\%; ${ }^{7}$ begitu pula di UGD RS Fatmawati Jakarta 65\%; di RS Prikasih 34,7\%.

Tingkat risiko ergonomi terhadap aktivitas angkat angkut pasien didapatkan skor REBA bernilai 11, menunjukkan tingkat risiko ergonomi yang sangat tinggi, sedangkan pekerjaan yang dilakukan dengan membungkuk, tingkat risiko ergonominya bervariasi. Tingkat risiko rendah ditemukan pada pengukuran tekanan darah, karena posisi membungkuk dikerjakan tanpa beban dalam waktu hanya 1-2 menit. Tingkat risiko menengah atau sedang saat pemasangan infus, kateter atau menjahit luka, hal ini berhubungan dengan pekerjaan tanpa beban namun dilakukan dalam durasi waktu yang cukup lama yaitu 5-10 menit, ditambah lagi frekuensi yang tinggi saat banyak pasien yang memerlukan bantuan ini. Tingkat risiko tinggi pada pekerjaan membuang urin pasien, karena selain postur janggal juga dibebani berat urin dalam pot serta frekuensi yang berulang-ulang dalam melaksanakan perawatan di UGD maupun di unit rawat inap.

Membungkuk merupakan posisi pekerjaan perawat yang tidak mungkin dihindari terutama saat memberikan pelayanan kepada pasien yang sedang berbaring di tempat tidur, membungkuk adalah posisi membelokkan tulang punggung ke arah frontal yang tentu akan membebani diskus intervertebralis, dan juga meningkatkan kontraksi ligamen dan otot-otot penyangga tulang belakang. Postur membungkuk adalah postur yang sangat berisiko, karena saat fleksi terjadi ketegangan otot (strain) terutama pada ligamentum interspinosus dan supraspinosus, diikuti dengan ligamentum intraskapular dan ligamentum flavum. Selain itu, beban kompresif pada diskus sewaktu fleksi membuat diskus berpotensi dapat merobek anulus fibrosis, akibatnya nucleus pulposus mampu keluar melalui robekan ini. Keluarnya nucleus pulposus (hernia nucleus pulposus) selanjutnya dapat menekan akar saraf spinal, bila pekerjaan membungkuk itu sering dilakukan, maka ligamen dan otot-otot penyangga tulang belakang dapat melemah dan selanjutnya meningkatkan tekanan pada diskus intervertebral. Proses berikutnya dapat merusak lapisan diskus intervertebral dan bila keadaan terus berlanjut dan/atau mendapat beban yang berat seperti mengangkat dan memindahkan pasien, maka kerusakan diskus intervertebralis dapat berlanjut menjadi kerusakan pada tulang vertebra yaitu iritasi vertebra bahkan dapat terjadi fraktur vertebra. Maka di sinilah pentingnya mengidentifikasi dan menilai risiko ergonomik, 
agar dapat dilakukan pengendalian risiko sedinidininya sebelum terjadi penyakit yang menetap, karena penanganan kasus yang sudah lanjut untuk kembali seperti semula sangatlah sulit walaupun dilakukan operasi.

Hasil penelitian analisis bivariat menunjukkan hubungan yang bermakna postur membungkuk dengan keluhan tingkat risiko LBP $(p=0,025)$, postur kerja membungkuk memiliki risiko 14 kali lebih sering terjadi keluhan LBP dibandingkan dengan postur kerja tidak membungkuk. Hasil ini sejalan dengan beberapa penelitian yang menyatakan bahwa 80 sampai $90 \%$ keluhan LBP karena membungkuk ke depan (fleksi). Hasil analisis bivariat ini menguatkan hasil observasi yang mempergunakan metode REBA bahwa pekerjaan membungkuk dan juga angkat angkut pasien adalah pekerjaan perawat yang paling berisiko LBP. Proses transfer pasien merupakan pergerakan simultan yang banyak membebani tulang belakang, otot, dan juga ligamen yang menunjang tulang belakang. Postur janggal dan beban membuat otot, tulang, dan ligamen pada vertebra berkontraksi maksimal sehingga bila dilakukan terus menerus dalam durasi yang lama dan sering maka dapat menimbulkan kelelahan pada otot akibat menumpuknya sisa metabolisme berupa asam laktat, yang diikuti kelemahan ligamen dan selanjutnya terjadi keluhan LBP. Pada penelitian ini, didapatkan hubungan yang bermakna antara kegiatan transfer pasien dan tingkat risiko LBP $(p=0,011)$. Analisis selanjutnya menunjukkan transfer pasien lebih dari 3 kali per hari berpeluang 4 kali lebih sering terjadi keluhan LBP dibandingkan dengan transfer pasien kurang dari 3 kali per hari karena lebih tinggi risiko ergonmoinya. Dengan demikian, prevalensi LBP yang lebih rendah di RSS terkait dengan frekuensi angkat angkut yang lebih rendah pula, karena kapasitas 6 tempat tidur periksa setiap harinya sekitar 25 pasien dilayani oleh 16 orang perawat. Jika dibandingkan dengan kapasitas ruang Rawat Tahanan RS Bhayangkara sebanyak 35 tempat tidur, BOR $80-90 \%$, hanya mempekerjakan 22 orang perawat, pasien yang dirawat sering disertai dengan penurunan kesadaran atau mengalami trauma kepala karena dihakimi massa, sehingga lebih banyak pasien yang memerlukan bantuan mobilisasi dibandingkan dengan ruang Rawat Inap pada umumnya. Juga UGD di RSUD Tarakan yang sangat sibuk dengan 40 tempat tidur periksa, tercatat sekitar 80 pasien per hari yang dilayani oleh 36 orang perawat. Semua perawat bekerja rotasi dalam 3 shift 4 grup.

Tinggi badan memengaruhi besarnya sudut lengkung punggung saat perawat melakukan tindakan terhadap pasien yang sedang berbaring di tempat tidur. Semakin besar sudut lengkung yang terjadi, maka kontraksi otot dan ligamen akan meningkat sehingga dapat melemahkan otot dan ligamen yang menyangga tulang belakang. Kondisi ini menyebabkan keluhan LBP karena diskus vertebra dapat tergelincir yang selanjutnya memiliki potensi menekan diskus intervertebralis dan akhirnya menekan saraf percabangan dari medula spinalis. Pada penelitian ini, didapatkan hubungan bermakna lengkung punggung dengan tingkat risiko LBP $(p=0,024)$, analisis lebih lanjut juga membuktikan bahwa sudut lengkung punggung lebih atau sama dengan $60^{\circ}$ berpeluang 11 kali lebih sering dapat meningkatkan risiko ergonomi apabila dibandingkan dengan sudut lengkung punggung lebih kecil dari $60^{\circ}$. Keadaan ini sejalan dengan meningkatnya risiko ergonomi dapat meningkatkan keluhan LBP.

Karakteristik individu perawat pada penelitian ini yang berhubungan dengan LBP adalah tinggi badan, kebiasaan merokok, dan jenis kelamin. Semakin tinggi tubuh perawat semakin berisiko mengalami LBP, perokok lebih berisiko terserang LBP bila dibandingkan dengan bukan perokok, dan perempuan lebih berisiko terserang LBP dibandingkan dengan laki-laki. Hasil penelitian ini walaupun sejalan dengan banyak penelitian lain, namun berbeda dengan hasil survei global yang menyimpulkan bahwa tingkat risiko LBP pada perawat tidak dipengaruhi oleh teknik perawatan, karakteristik personal, dan faktor risiko di luar pekerjaan. ${ }^{8}$ Perbedaan ini dapat dijelaskan karena uji statistik pada penelitian ini adalah bivariat sehingga yang didapat adalah crude OR dan belum memperhitungkan interaksi antarvariabel yang mungkin menjadi perancu, sedangkan fokus penelitian ini adalah pada alat kerja dan proses kerja. Bila karekeristik individu yang menjadi fokus utama maka diperlukan sampel responden yang lebih besar dengan uji multivariat agar didapat adjusted OR untuk penilaian kemaknaan yang akurat.

Penelitian mendapatkan bahwa alat kerja yang paling dominan berkontribusi yang meningkatkan risiko ergonomi dan LBP adalah tempat tidur dan brankar, keadaan ini merupakan signal untuk melakukan perbaikan sesuai kaidah manajemen risiko yaitu tindakan perbaikan dini saat rambu 'action level' ditemukan. Tempat tidur di UGD dan ruang Rawat Inap yang rendah (kurang atau sama dengan $60 \mathrm{~cm}$ ) memaksa perawat untuk membungkukkan badannya pada waktu memberikan pelayanan, begitu pula perbedaan 25-30 cm antara tinggi tempat tidur dan brankar transportasi memaksa perawat membungkukkan badan saat mengangkat dan juga memindahkan pasien. Hal ini tidak terjadi pada perawat UGD di RSS karena semua tempat tidur dan brankar dapat diturun-naikkan (rentang 45-72 cm) sesuai 
tinggi badan si perawat. Disimpulkan faktor fisik seperti posisi janggal, manual handling, sering membungkuk (frequent bending) dan memutar (twisting), serta gerakan mendorong ke depan merupakan faktor risiko yang dapat memengaruhi tingginya prevalensi LBP pada perawat tersebut.

Fokus yang paling utama untuk pengendalian risiko seyogianya diarahkan pada faktor risiko utama yang teridentifikasi, sesuai dengan prinsip manajemen risiko dan tujuan ergonomi yaitu seni penerapan teknologi untuk menyerasikan dan menyeimbangkan sarana yang digunakan dengan kemampuan dan keterbatasan manusia baik fisik maupun mental. ${ }^{17}$ Risiko LBP pada perawat dapat dikurangi, ${ }^{18}$ sesuai dengan hirarki pengendalian risiko di dalam bidang keselamatan dan kesehatan kerja, dengan demikian maka pengendalian teknik diutamakann dalam pengendalian risiko akibat pekerjaan membungkuk, disusul pengendalian adminstratif dan baru terakhir mempergunakan alat pelindung diri bila masih tersisa risiko yang tidak dapat diterima. Disarankan menggunakan tempat tidur yang tingginya dapat disesuaikan seperti di RSS, dengan demikian perawat dapat menyesuaikan tinggi tempat tidur dengan tinggi badannya sehingga mengurangi sudut lengkung punggung. Selain itu, juga perlu untuk disediakan tempat duduk yang tingginya dapat dinaikkan atau diturunkan, agar perawat dapat menyesuaikan tinggi tempat tidur sejajar dengan bagian bawah siku lengan atasnya saat memberikan pelayanan dengan durasi lebih dari dua menit dan berulangulang, seperti pada saat menjahit luka, menyuntik intravena, dan juga memasang infus pada pasien dehidrasi. Pasien dehidrasi sering kali mengalami hipotensi dan venanya seolah-olah menghilang sehingga sulit untuk dapat dijangkau. Selanjutnya, sudut lengkung tubuh juga perlu dikurangi saat mengukur urin, disarankan menyediakan meja atau troli agar perawat dapat bekerja dengan tubuh tegak, meja dinding selebar $30 \mathrm{~cm}$ dalam kamar mandi, atau toilet juga merupakan solusi yang baik.

Begitu pula, pekerjaan untuk dapatmengangkat dan memindahkan pasien disarankan agar dapat menggunakan tempat tidur rawat dan brankar pasien yang ketinggiannya dapat disesuaikan, dengan demikian kesenjangan ketinggian antara tempat tidur dan juga brankar transportasi dapat dihindari, maka postur membungkuk juga dapat diminimalkan. Selain itu, untuk mengurangi beban dan frekuensi, maka rasio jumlah-perawat pasien minimal harus dipenuhi, perawat harus dilatih agar pekerjaan mengangkat dan memindahkan pasien minimal dilakukan oleh 2 orang perawat, yang kompeten dalam teknik pemindahan pasien, perawat yang tidak terlatih terbukti merupakan faktor risiko LBP yang signifikan. ${ }^{19}$
Untuk mengendalikan faktor risiko somatik yaitu bahaya yang bersumber dari tubuh perawat, maka perawat harus dapat mengenal faktor risiko LBP dan cara pengendaliannya. Untuk itu perlu dilakukan komunikasi hazard dan pelatihan, mereka juga dianjurkan melakukan peregangan otot sebelum dan sesudah melakukan pekerjaan ini, olahraga secara teratur untuk meningkatkan kekuatan dan kelenturan otot penyangga tulang belakang. Selain itu, jangan merokok oleh karena kebiasaan merokok terbukti berperan sebagai faktor risiko LBP. ${ }^{20}$

Simpulan penelitian ini mendapatkan keluhan LBP paling tinggi pada perawat UGD di RSUD Tarakan dan cukup tinggi pada perawat rawat inap di RS Bhayangkara. Prevalensi yang rendah pada perawat UGD di RSS bila dibandingkan dengan prevalensi LBP yang tercatat dari global survei; teridentifikasi aktivitas pekerjaan yang dominan menimbulkan LBP pada perawat UGD dan ruang Rawat Inap adalah membungkuk dan angkat angkut pasien. Disimpulkan terdapat hubungan hazard ergonomi berupa postur membungkuk, sudut lengkung punggung, dan kekerapan transfer pasien dengan tingkat risiko LBP. Selain itu, karakteristik individu yang berhubungan dengan keluhan LBP adalah jenis kelamin, tinggi badan, dan kebiasaan merokok.

Untuk menurunkan risiko ergonomi yang diperkirakan berhubungan dengan LBP, pihak manajemen rumah sakit (RS) seyogianya dapat melakukan pengendalian teknik dan pengendalian administratif. Pengendalian teknik yaitu dengan memakai tempat tidur dan brankar transportasi yang adjustable sebagai pengganti model statis, menyediakan bangku adjustable untuk pekerjaan membungkuk pada saat memberikan pelayanan pasien yang sedang berbaring di tempat tidur, dan menyiapkan 'meja' dinding di toilet untuk pengukuran urin. Pengendalian administratif yaitu mengurangi beban dan frekuensi tugas berisiko LBP dengan memenuhi rasio perawatpasien minimal, menyusun SOP, memberikan pendidikan dan pelatihan teknik pengendalian risiko yaitu minimal tentang komunikasi hazard, teknik angkat angkut pasien, teknik peregangan otot, tidak merokok, melakukan kegiatan olahraga teratur untuk dapat meningkatkan kekuatan dan kelenturan otot penyangga tulang belakang, dan berperilaku kerja yang baik dengan mengikuti SOP. Penelitian lebih lanjut dalam skala lebih besar dengan besar sampel yang adekuat perlu dilakukan dalam rangka melakukan penilaian risiko yang lebih teliti; selain itu, penelitian ini seyogianya dilanjutkan dengan penelitian pre and post controlled group design untuk meyakini keberhasilan intervensi. 


\section{Ucapan Terima Kasih}

Kami mengucapkan banyak terima kasih kepada pimpinan Rumah Sakit atas izin yang diberikan sehingga penelitian ini dapat terlaksana dengan baik. Terima kasih juga kami ucapkan kepada Dr. Chandra Satrya, M.App.Sc, Hendra SKM, MKKK, Dr. Lukman Hakum M.Kes, DFM dan Dr. Istiati Suraningsih, MKK atas kesediaannya dalam memberikan masukan, ide dan juga saran yang sangat berharga, kepada responden yang berpartisipasi, serta kepada rekan-rekan yang membantu dalam pengumpulan data penelitian ini.

\section{Daftar Pustaka}

1. European Foundation for the Improvement of Living and Working Conditions, Annual Review of Working Condition in the European Union [online] 2006-2007 (diunduh 8 Juni 2012). Tersedia dari: www.eurofound.europa. eu

2. U.S. Department of Labor Bureau of Labor Statistics; 2006.

3. Kurniawidjaja LM. Laporan Penyakit akibat kerja dan absenteisme di pabrik semen X 2006. Bogor: Institusi; 2007.

4. Nelson A, Baptiste A S. Evidence-based practices for safe patient handling and movement. Clin Rev Bone Mineral Metabolism. 2006;4(1):55-69.

5. Advance healthcare network for nurses, Resolving back pain in nurses [online] (diunduh 9 Maret 2012). Tersedia dari: http:// nursing.advanceweb.com/article

6. Karahan A, Kav S, Abbasoglu A, Dogan N. Low back pain: prevalence and associated risk factors among hospital staff. J Adv Nurs. 2009;65(3):516-24.

7. Schoenfisch AL, Lipscomb HJ, Pompeii LA, Myers DJ, Dement JM. Musculoskeletal injuries among hospital patient care staff before and after implementation of patient lift and transfer equipment. Scan J Work Env Health. 2013;39(1):27-36.

8. Yassi A, Lockhart K. Work-relatedness of low back pain in nursing personnel: a systematic review. IJOEH. 2013;19(3):223-44.

9. Roupa Z, Vassilopoulos A, Sotiropoulou
P, Makrinika E, Noula M, Faros E, dkk. The problem of lower back pain in nursing staff and its effect on human activity. HSJ. 2008;2(4):219-25.

10. Kurniawidjaja LM. Teori dan aplikasi kesehatan kerja. Cetakan ke-3. Jakarta: UI Press; 2012.

11. Setyohadi B. Etiopatogenesis nyeri pinggang, Temu ilmiah rematologi dan kursus nyeri. Jakarta: IRA; 2005.

12. Direktorat Jenderal Pembinaan dan Pengawasan Ketenagakerjaan Program Perlindungan dan Pengembangan Lembaga Tenaga Kerja. Himpunan Peraturan Perundangan Kesehatan Kerja. Jakarta: 2010.

13. REBA Employe Assesment work sheet. 2004 (diunduh 25 Februari 2012). Tersedia dari: http://personal.health.usf.edu/tbernard/ HollowHills/REBA.pdf.

14. Eriksen W, Bruusgaard D, Knardahl S. Work factors as predictors of intense or disabling low back pain; a prospective study of nurses' aides. Occup Environ Med. 2004;61(5):398404.

15. Kim H, Dropkin J, Spaeth K, Smith F, Moline J. Patient handling and musculoskeletal disorders among hospital workers: analysis of 7 years of institutional workers' compensation claims data. Am J Ind Med. 2012;55(8):68390.

16. Yip V. New low back pain in nurses: work activities, work stress and sedentary lifestyle. J Adv Nurs. 2004;46:430-40.

17. Tarwaka. konsep dasar ergonomic, ergonomi untuk keselamatan, kesehatan kerja dan produktivitas. Surabaya: Uniba Press; 2004.

18. Rasmussen CD, Holtermann A, Mortensen OS, Søgaard K, Jørgensen MB. Prevention of low back pain and its consequences among nurses' aides in elderly care: a stepped-wedge multi-faceted cluster-randomized controlled trial. BMC Public Health. 2013;13:1088.

19. Wong TS, Teo N, Kyaw MO. Prevalence and risk factors associated with low back pain among health care providers in a district hospital. Malay Ortho J. 2010;4(2):23-8.

20. Paula M, Päivi LA, Jouko R, Paavo Z, Simo $\mathrm{T}$, Jaro K. Is smoking a risk factor for low back pain in adolescents?: a prospective cohort study. Spine. 2008;33(5):527-32. 